\title{
PATTERNS OF PEDIATRIC EAR, NOSE AND THROAT DISORDERS IN A TERTIARY CARE HOSPITAL OF WESTERN NEPAL: A CROSS-SECTIONAL STUDY
}

\author{
Shiva Regmi, ${ }^{1}$ Nagendra Chaudhary, ${ }^{2}$ Sandeep Shrestha, ${ }^{2}$ Santosh Pathak, ${ }^{3}$ Badri Kumar Gupta, ${ }^{2}$ Ravi Swar, ${ }^{4}$ Om Prakash Kurmi ${ }^{5,6}$
}

\begin{abstract}
INTRODUCTION

In outpatient department (OPD) of hospital in low and middle income countries (LMICs), pediatric ear, nose and throat (ENT) disorders are common and huge variation in number is being reported in different seasons. This study aimed to study the prevalence and seasonal effect of ENT disorder in children.
\end{abstract}

\section{MATERIAL AND METHODS}

One year (Jan-Dec, 2015) retrospective data of children (0 months-17 years) visiting ENT outpatient (ENT-OPD) department at Universal College of Medical Sciences-Teaching Hospital, Nepal was analysed. Descriptive statistics were calculated to report the prevalence of ENT disorders for various sub-groups including season. In addition to quantifying the prevalence of ENT disorders in children, the seasonal influence of each disorder was analysed.

\section{RESULTS}

Out of 14,126 patients visiting the ENT-OPD, 3,423 (24.23\%) were children. The mean age of children having ENTdisorders were $8.4 \pm 5.1,10.6 \pm 4.6$ and $10.7 \pm 4.7$ years respectively with male-female ratio of 1.3:1.

During all seasons 2,645 (77.3\%) had ear problems, $328(9.6 \%)$ nose disorders and $450(13.14 \%)$ throat disorders. The percentage of children with ear disorders declined significantly with increase in age unlike those with nose and throat disorders $(\mathrm{P}<0.001)$. Seasonal trend analysis showed that children had significantly higher number of ear disorders during summer and autumn seasons $(\mathrm{P}<0.001)$ whereas nose disorders were more common in spring and winter seasons $(\mathrm{P}$ $<0.001$ ) with chronic otitis media and wax being the main types of ear disorders and deviated nasal septum (DNS) for nose disorders. Among the throat disorders, tonsillitis was most prevalent in all seasons followed by pharyngitis.

\section{CONCLUSION}

The study suggests a clear seasonal trend in the prevalence of ENT disorders that can be used for advanced planning and management of the conditions in hospitals.

KEYWORDS ENT disorders, Chronic otitis media, Wax, Allergic rhinitis, Tonsillitis.

1. Department of ENT, Devdaha Medical College and Research Institute, Rupandehi, Nepal

2. Department of Pediatrics, Universal College of Medical Sciences, Bhairahawa, Nepal

3. Department of Pediatrics, Chitwan Medical College, Bharatpur, Nepal

4. Department of ENT, Universal College of Medical Sciences, Bhairahawa, Nepal

5. Population Health Research Institute, Department of Medicine, McMaster University, Hamilton, Canada

6. Division of Respirology, Department of Medicine, McMaster University, Hamilton, Canada

DOI: http//doi.org/10.3126/jucms.v7i2.27129

For Correspondence

Dr. Nagendra Chaudhary

Department of Pediatrics,

Universal College of Medical Sciences

Bhairahawa, Nepal

Email: enagendra@hotmail.com 


\section{INTRODUCTION}

Children presenting with ear, nose and throat disorders to the Ear, Nose and Throat (ENT) outpatient department are common in many low and middle income countries (LMICs) including Nepal. ${ }^{1}$ Although the pattern of ENT disorders varies within communities and different geographical region but it is more common in children compared to adults due to their under developed immunity, malnutrition, poor hygiene and sanitations, low socioeconomic condition and overcrowding.

School absenteeism due to ENT diseases is quite common in children from LMICs that significantly affect their learning and hence psychological development. ${ }^{2}$ Wider and horizontal eustachian tube is also one of the important reasons for increased ear infections in children leading to hearing impairment. ${ }^{3,4}$

Some studies suggest that the number of children visiting for ENT disorders at medical facilities varies at different period of the year but it is not clear how geographical area, seasonality, ethnicity, and socioeconomic status influence the pattern of ENT diseases in Nepalese tertiary hospitals. This study aims to find different patterns of ENT diseases in paediatric population along with the seasonal variation in Western part of Nepal.

\section{MATERIAL AND METHODS}

This retrospective cross-sectional study was conducted by the department of ENT at Universal College of Medical SciencesTeaching Hospital (UCMS-TH), a tertiary care referral hospital situated in Rupandehi District of Western region of Nepal. The study was approved by the Institutional Review Board (IRB). The data of children visiting ENT OPD, aged from one day to 17 years, over one-year period (1 January 2015 to 31 December 2015) were collected from the record section of the hospital. Any missing data on children visiting the ENT OPD were excluded from the study. Children were grouped into infants, toddlers, pre-schoolers, middle childhood, young teens and teenagers for analysis according to the centres for disease control and prevention (CDC). ${ }^{5}$

The health outcomes as diagnosed by otorhinolaryngologist were grouped into three broad categories which were further sub-grouped based on sub-types of each broad category. The three categories included ear disorders, nose disorders and throat disorders. All the diagnoses were made based on detailed history, clinical presentation, and appropriate investigations.

Descriptive analysis (crude mean, percentage, and proportion) was calculated. Chi-square $\left(\mathrm{x}^{2}\right)$ test was used to test the trend or heterogeneity for ordinal (age-group) and various categorical variables. Bar diagrams were prepared for different ENT outcomes by age-groups, seasons or gender. Data analysis was carried out in Stata (version 13).

\section{RESULTS}

Out of 14,126 patients visiting the ENT outpatient department (ENT OPD), 3423 (24.23\%) were of paediatric age groups (Figure 1). The mean age of children having ENT disorders were $8.4 \pm 5.1$ years, $10.6 \pm 4.6$ years and $10.7 \pm 4.7$ years respectively with male: female ratio of $1.3: 1$.

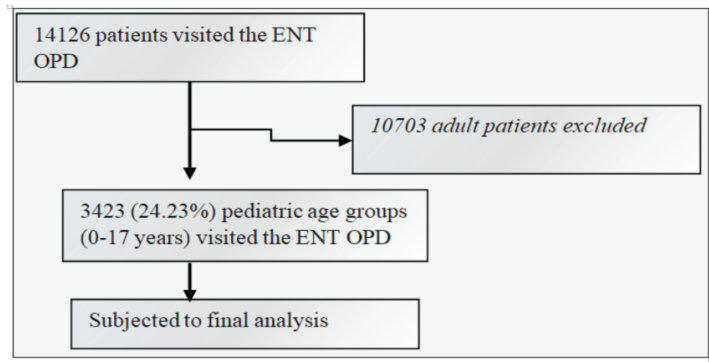

Figure 1. Showing flow diagram of patients visiting the ENT OPD during the study period

Of the total children visiting ENT OPD, 77.3\% (2645) had ear disorders, 9.6\% (328) had nose disorders and 13.14\% (450) had throat disorders. Ear problem was the major leading cause for children visit to the ENT OPD followed by throat and nose disorders in all age groups (Figure 2).

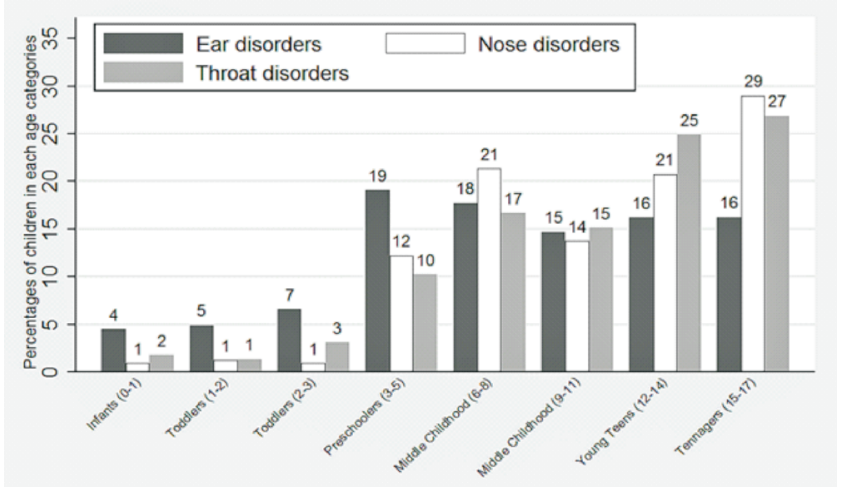

Figure 2. ENT disorders in children by age-groups visiting a tertiary-hospital in Western Nepal

Children presenting with ear disorders had a significant decline in proportion as age advanced, i.e. more in infants and least in teenagers, whereas proportion of children with nose and throat disorders increased significantly with age (P-test for trend $<0.001$ for ear, nose and throat disorders respectively) (Table 1).

The proportion of ear disorders were significantly $(\mathrm{p}<0.005)$ 
higher in children from Terai region (72.8\%) when compared to hilly $(60.9 \%)$ and Terai-Indian $(72 \%)$ unlike nose and throat disorders which was higher in Terai-India and hilly regions respectively (Table1). Although there was no difference in the proportion of children visiting ENT OPD based on the religious sub-groups but significantly higher proportion of Muslim children visited the ENT OPD with nose disorders compared to Hindu children $(\mathrm{p}=0.004)$.

Seasonal trend analysis showed significantly higher number of ear disorders in summer and autumn seasons $(p<0.001)$ whereas nose disorders were more common in spring and winter seasons $(p<0.001)$. Throat disorders was more prevalent in spring and summer seasons $(\mathrm{p}<0.002)$ (Table 1$)$.

Table 1. Characteristics of children visiting the ENT outpatient department

\begin{tabular}{|c|c|c|c|c|}
\hline \multirow[t]{2}{*}{ Characteristics } & \multicolumn{2}{|r|}{ Ear disorders } & \multirow{2}{*}{$\begin{array}{c}\text { Nose } \\
\text { disorders } \\
\text { N (\%) }\end{array}$} & \multirow{2}{*}{$\begin{array}{c}\text { Throat } \\
\text { disorders } \\
\text { N }(\%)\end{array}$} \\
\hline & Total & $\mathrm{N}(\%)$ & & \\
\hline Children (Age in years) & & 2645 & 328 & 450 \\
\hline Infant (0-1) & 134 & $119(88.8))$ & $3(2.2)$ & $8(6.0)$ \\
\hline Toddlers $(1-2)$ & 151 & $130(86.1))$ & $4(2.6)$ & $6(4.0)$ \\
\hline Toddlers (2-3) & 202 & $174(86.1))$ & $3(1.53)$ & $14(6.9)$ \\
\hline Pre-schoolers (3-5) & 642 & $505(78.7)$ & $40(6.2)$ & $46(7.2)$ \\
\hline Middle childhood (6-8) & 646 & $469(72.6)$ & $70(10.8)$ & $75(11.6)$ \\
\hline Middle childhood (9-11) & 532 & $389(73.1)$ & $45(8.5)$ & $68(12.8)$ \\
\hline Young teens (12-14) & 651 & $429(65.9)$ & $68(10.4)$ & $112(17.2)$ \\
\hline Teenagers (15-17) & 704 & $430(61.1)$ & $95(13.5)$ & $121(17.2)$ \\
\hline Mean \pm SD & & $8.4 \pm 5.1$ & $10.6 \pm 4.6$ & $10.7 \pm 4.7$ \\
\hline p-test for trend & & $<0.001$ & $<0.001$ & $<0.001$ \\
\hline \multicolumn{5}{|l|}{ Gender } \\
\hline Male & 2060 & $1483(72.0)$ & $200(9.7)$ & $250(12.1)$ \\
\hline Female & 1602 & $1162(72.5)$ & $128(8.0)$ & $200(12.5)$ \\
\hline p-test for heterogeneity & & 0.715 & 0.071 & 0.75 \\
\hline \multicolumn{5}{|l|}{ Region } \\
\hline Terai & 3170 & $2308(72.8)$ & $270(8.5)$ & $396(12.5)$ \\
\hline Hilly & 156 & $95(60.9)$ & $17(10.9)$ & $29(18.6)$ \\
\hline Terai (Indian) & 336 & $242(72.0)$ & $41(12.2)$ & $25(7.4)$ \\
\hline p-test for heterogeneity & & 0.005 & 0.055 & 0.001 \\
\hline \multicolumn{5}{|l|}{ Religion } \\
\hline Hindu & 3006 & $2178(72.5)$ & $250(8.3)$ & $382(12.7)$ \\
\hline Muslim & 656 & $467(71.2)$ & 78 (11.9) & $68(10.4)$ \\
\hline $\begin{array}{l}\text { p-test for heterogeneity } \\
\text { Seasons }\end{array}$ & & 0.512 & 0.004 & 0.098 \\
\hline Spring (March-May) & 932 & $617(66.2)$ & $111(11.9)$ & $148(15.9)$ \\
\hline Summer (June- August) & 1303 & $989(75.9)$ & $89(6.8)$ & $147(11.3)$ \\
\hline Autumn (September-November) & 578 & $462(79.9)$ & $48(8.3)$ & $61(10.5)$ \\
\hline Winter (December-February) & 849 & $577(68.0)$ & $80(9.4)$ & $94(11.1)$ \\
\hline p-test for heterogeneity & & $<0.001$ & 0.001 & 0.002 \\
\hline
\end{tabular}

Among all ENT disorders, chronic otitis media and wax were the most prevalent ear disorders as were deviated nasal septum
(DNS) and allergic rhinitis for nose disorders and tonsillitis and pharyngitis for throat disorders (Figures 3- 5).

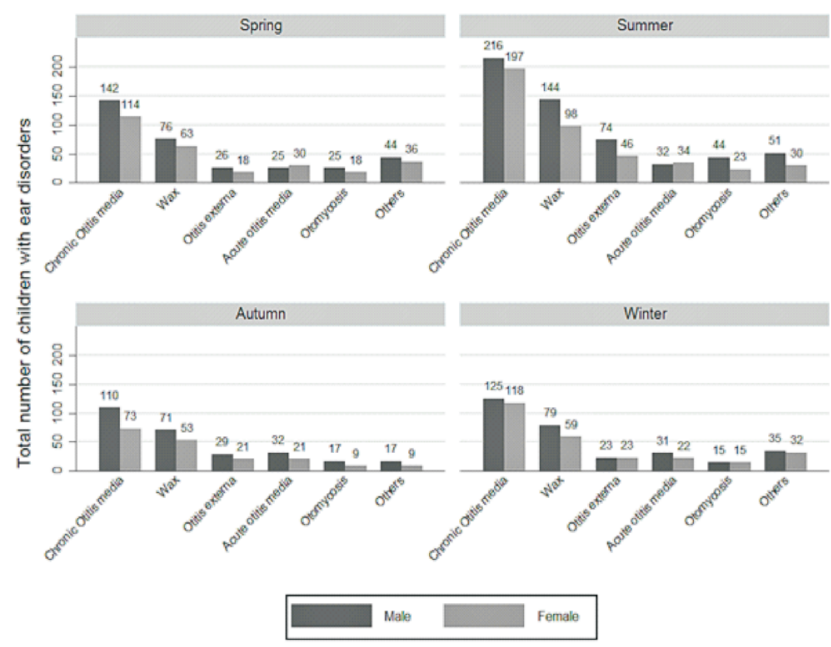

Figure 3. Pattern of different ear disorders in children visiting a tertiary-hospital in Western Nepal

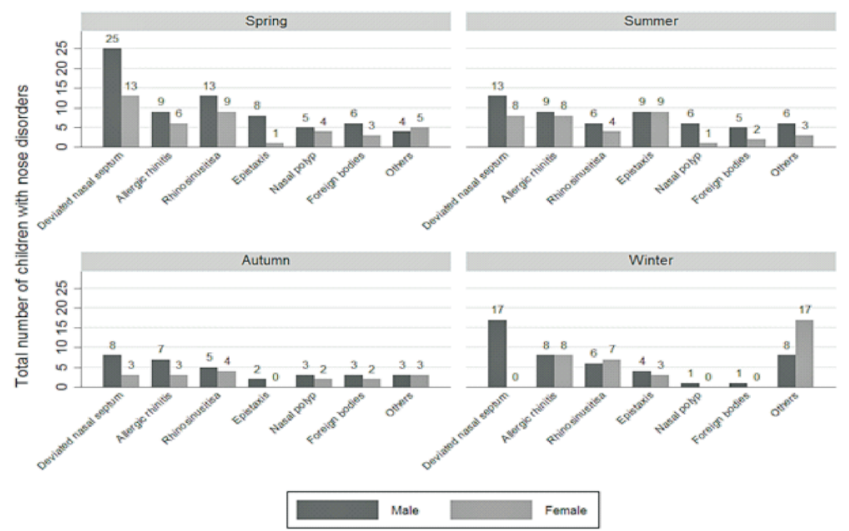

Figure 4. Pattern of nose disorders in children visiting a tertiary-hospital in Western Nepal

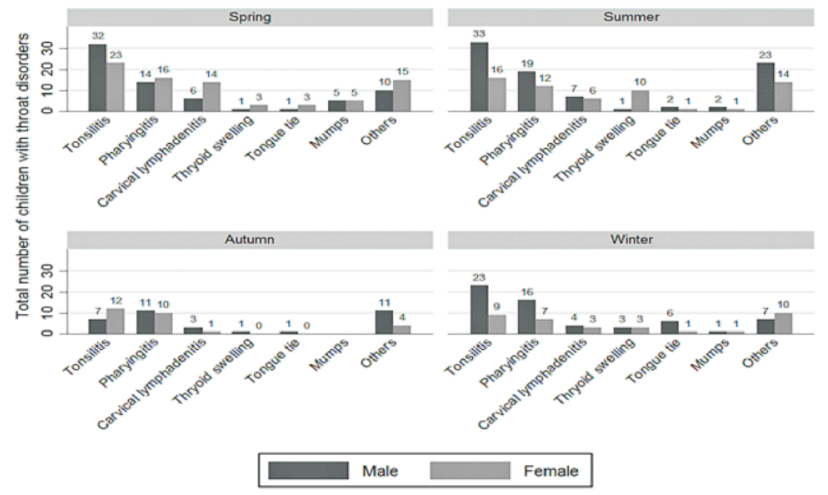

Figure 5. Pattern of throat disorders in children visiting a tertiary-hospital in Western Nepal 


\section{DISCUSSION}

There is paucity of epidemiological data from LMICs including Nepal on determinants of pediatric ear, nose and throat (ENT) disorders. The result from this retrospective study suggests that ear disorders decreases with increase in age in children unlike nose and throat disorders which increased with increase in age. Our result suggests that the proportion of children visiting ENT OPD with ear disorders is the highest in summer and autumn season compared to winter and spring.

A total of $3,423(24.23 \%)$ children visited the ENT OPD during the one year study period of this study suggesting that children comprise a greater proportion of total patients among those who seek consultation with otorhinolaryngologist in LMICs. The prevalence of children visiting ENT OPD in a study conducted by Symvoulakis et al (2006, Greece) was relatively lower $(886,13.1 \%)$ than our study. ${ }^{6}$

Previous studies from LMICs including Nepal suggest that the prevalence of ear related disorders ranged from $21.5 \%$ to $81.6 \%{ }^{7-12}$ In our study, over two-thirds $(77 \%)$ of the total children visiting the ENT OPD department had ear related disorders contrary to previous study carried out by Sigdel et al (2012) who reported lower proportion (58\%). ${ }^{11}$ The sample size in our study was larger than that reported by Sigdel et al (3423 versus 1632 children) and data in our study was collected for one complete year.

Among the previous published studies, prevalence of chronic otitis media ${ }^{13-16}$ and wax ${ }^{9,10,17-20}$ were the two most prevalent ear disorders in LMICs including in Nepal. A study from the Western part of the Nepal in younger age groups (6-10 years) reported higher prevalence of wax $(33.4 \%)$ followed by chronic otitis media (COM) $(24.3 \%)$ unlike in our study where the prevalence of wax (24.3\%) was lower compared to COM $(41.3 \%){ }^{11}$ Similarly, another study carried out in rural Nepal sampled 5-13 year old children from health camps conducted in school reported that children has over two-folds $(62 \% ; 1240$ out of 2000) prevalence of wax compared to the findings from our study. ${ }^{7}$ A study from Eastern part of Nepal in school going children with age-groups 5-15 year reported the prevalence of chronic otitis media to be $13.2 \%{ }^{15}$, in line with that of reported by Biswas et $\mathrm{al}^{14}$, Morris etal ${ }^{21}$ and Maharjan et al ${ }^{15}$ which were $12.4 \%, 15 \%$ and $13.2 \%$ respectively from various parts of Nepal. Minja and Machemba (1996) reported higher prevalence of COM in rural school children compared to that of urban $(9.44 \%$ versus $1.3 \%$; $>0.001)$ probably suggesting the effect of low socio-economic status. ${ }^{10}$ Previous population data from Nepal had reported that the overall prevalence of otitis media is around $16 \%$ in those with low socioeconomic status and majority of them $(>55 \%)$ occurring in school going children. ${ }^{22}$ Although many studies have suggested that socioeconomic status including illiteracy are likely to be the one of the major risk factors for ear disorders, the huge variation of COM in various studies suggest need for larger studies over longer duration to find the true burden and determinants of COM in children. The wide variation in sub-types of ear disorders from different studies could be due to number of factors including socioeconomic status, hygiene of the dwelling, age groups of children or environmental conditions in the region from where samples were recruited. It could also be due to reporting bias as wax is generally asymptomatic in majority of children and some may not have had medical advice.

The increase burden on ear disorders particularly in LMICs could lead to mild to moderate hearing loss. ${ }^{14}$ A study conducted in rural school of south India reported that $53.4 \%$ of children with middle ear disease had hearing impairment whereas $91.2 \%$ of children with hearing impairment had middle ear disease; indicating the importance of prevalence of ear disorders and hearing impairment. ${ }^{9}$

DNS was the most common nose disorders followed by allergic rhinitis and rhinosinusitis in our study whereas a study conducted in India showed rhinitis to be more common followed by chronic sinusitis. ${ }^{12}$ The proportion of children with epistaxis $(10.98 \%)$ in our study was lower than studies conducted by Sanjay et al $(16.6 \%)$ and Yeli et al $(15 \%))^{1,23}$ Local inflammatory conditions, infections, and trauma due to nose picking are important causes for epistaxis in children. ${ }^{24}$ In addition, dryness of nasal mucosa in summers and use of heating appliances in winters may be the reason for higher proportion of epistaxis in some studies.

Among the throat disorders, tonsillitis $34.4 \%$ (155 out of 450 ) was the most common throat problem for pediatric ENT patients followed by pharyngitis. Similar results were seen in a study carried out in Telangana, India although pharyngitis was more common than tonsillitis in their study. ${ }^{12}$ A study done by Yeli et al also suggested a high prevalence of tonsillitis whereas Nepali et al had more proportion of children with pharyngitis. $^{19,23}$

Overall proportion of ENT disorders in the present study was least in infants and toddlers; and more in teens and teenagers. The reason of least proportion of infants visiting the ENT OPD could be because they are generally seen by a general paediatrician. In our study, the ear infections was predominantly more in infants $(88.8 \%$, p-test for trend $<0.001)$ with decreasing pattern as the age advanced. Nose and throat disorders showed opposite trend to ear infections with significant number in teenagers and lowest in infants ( $\mathrm{p}$ test for trend for both nose and throat disorders $<0.001$ ). In 
contrary, a study by Adhikari P reported that high proportion of children with ear disorders in 5-7 year age group (861 out of $2000 ; 43 \%$ ) and lowest in 11-13 year age group (486 out of $2000 ; 24.3 \%)^{7}$. The reason could be due to differences in study site (hospital versus school camps), cases recruitment (children visiting ENT OPD versus healthy school going children), and geographical location as well as variation in climatic conditions.

Although previous few studies in Nepal have focused on the prevalence and pattern of ENT disorders; none of them has reported the variation of ENT disorders with seasonality. We observed a significant seasonal variation on the occurrence of ENT disorders. Ear problems $(p<0.001)$ were the leading cause for hospital visit in all the seasons followed by throat $(p=0.002)$ and nose $(p=0.001)$ disorders respectively. Many children presented in the summer season with significant number of ear disorders whereas nose disorders and throat disorders were common in spring. Epistaxis was common in summer and spring seasons in our study whereas a study done in UK showed increased prevalence in winter and spring seasons. The increased incidence in our study can be explained by nasal mucosa dryness during the summer seasons whereas use of heating appliances in winters could also lead to nasal mucosa dryness precipitating epistaxis as also reported by a study conducted in UK. ${ }^{25}$ Another study by $\mathrm{V}$. Danielides et al suggested that the influence of weather on epistaxis is greater during the cold period of the year and especially under very cold and very dry conditions. ${ }^{26}$ A study conducted in Greece (2006) reported high proportion of overall ENT disorders in the month of March but did not specify sub-types of ENT disorders for that month; neither has it clearly clarified the exact seasonal variation of ENT disorders in children. ${ }^{6}$ The severity of nasal disorders based on nasal cytology showing neutrophilic infiltrates $(80 \%$ versus $52 \%$ ) in Australian aboriginal children was more common in winter than in spring, ${ }^{27}$ suggesting the role of seasonality.

The high prevalence of DNS and wax in summer and spring seasons could be due to large number of nose and ear disorders reporting to the hospital rather than the effect of seasons.

The main limitation of our study was that the study subjects were from a single hospital which might not reflect the overall burden from that geographical region suggesting that larger multicentre studies (in hospitals, schools, villages and towns) should be conducted in future to find the exact burden and seasonal variation of ENT disorders in children. The other main limitation is that the children visiting tertiary hospital care are more likely to be those with advanced stage of ENT disorders as hence it might not reflect the true burden of ENT disorders at community level.

\section{CONCLUSION}

Children with ear disorders have a greater ENT Outpatient visits with majority of them being infants and toddlers. Ear disorders and throat disorders are common in young teens and teenagers. The sub-types of ENT disorders visiting tertiary hospital varies by season. The prevalence and distribution of ENT diseases in LMICs including Nepal can help us to identify the disease burden, and consider appropriate measures in diagnosing, providing adequate treatment, and undertaking various preventive measures. Data on seasonal trends can further help us take appropriate steps for its management during outbreaks. Introducing School Health Services, health education and improvement of socioeconomic status can be helpful in reducing the burden and prevalence of ENT disorders.

\section{Conflict of Interest: None.}

\section{ACKNOWLEDGEMENTS}

We are grateful to the interns (Dr. Sunil Shah, Dr. Saugat Pradhan, Dr. Sameer Maskey, Dr. Sumit Gami and Dr. Subodh Bidari) for their support in data collection. We also thank the administrators of Universal College of Medical Sciences (UCMS) for making the data available for us.

\section{REFERENCES}

1. Kishve S., N. Kumar, P. Kishve S. Aarif and P. Kalakoti. Ear, Nose and Throat disorders in paediatric patients at a rural hospital in India. Australasian Medical Journal. 2010;3(12): p. 786-790.

2. Dzieciolowska-Baran, E., A. Gawlikowska-Sroka and M. Mularczyk. Diseases of the Upper Respiratory Tract in Preschool and School Age Children in Ambulatory Ear Nose Throat Practice. Adv Exp Med Biol. 2015;873: p. 35-41.

3. Finnbogadottir A.F., H. Petersen, T. Laxdal, F. Gudbrandsson, T. Gudnason and A. Haraldsson. Mastoiditis in children in Iceland. Laeknabladid. 2007;93(4): p. 275-80.

4. Gul A., L. Ali, E. Rahim and S. Ahmed. Chronic supporative otitis media: Frequency of Pseudomonas aeruginosa in patients and its sensitivity to various antibiotics. Professional Medical Journal. 2007;14(3): p. 411-415.

5. Centers for Disease Control and Prevention. Child Development. [cited 2019 May 2018].

6. Symvoulakis E.K., S. Klinis A. Alegakis, D.E. Kyrmizakis, E.I. Drivas, G. Rachiotis, A. Philalithis and G.A. Velegrakis. Epidemiologic profile of otorhinolaryngological, head and neck disorders in a tertiary hospital unit in Greece: a challenge for general practitioners? BMC Ear Nose Throat Disord. 2006;6: p. 12 
7. Adhikari P. Pattern of ear diseases in rural school children experiences of free health camps in Nepal. Int $\mathrm{J}$ Pediatr Otorhinolaryngol. 2009;73(9): p. 1278-80.

8. Basak B., G. Dhar, G. Gayen and R. Ray. Pattern of aural morbidity among children in a rural tertiary care hospital. IOSR Journal of Pharmacy. 2013;3(7): p. 58-62.

9. Jacob, A., V. Rupa, A. Job and A. Joseph. Hearing impairment and otitis media in a rural primary school in south India. Int $\mathrm{J}$ Pediatr Otorhinolaryngol. 1997;39(2): p. 133-8.

10. Minja B.M. and A. Machemba. Prevalence of otitis media, hearing impairment and cerumen impaction among school children in rural and urban Dar es Salaam, Tanzania. Int J Pediatr Otorhinolaryngol. 1996;37(1):p. 29-34.

11. Sigdel, B. and R. Nepali. Pattern of Ear Diseases among Paediatric ENT Patient: An Experience from Tertiary Care Centre, Pokhara, Nepal. Journal of Nepal Paediatric Society. 2012;32(2): p. 142-145.

12. Surapaneni H, Sisodia SS. Incidence of ear, nose and throat disorders in children: a study in a teaching hospital in Telangana. International Journal of Otorhinolaryngology and Head and Neck Surgery. 2016 Jan 7;2(1):26-9.

13. Akinpelu OV, Amusa YB. Otological diseases in Nigerian children. Internet J Otorhinolaryngol. 2007;7:1-6.

14. Biswas, A.C., A.H. Joarder and B.H. Siddiquee. Prevalence of CSOM among rural school going children. Mymensingh Med J. 2005;14(2): p. 152-5.

15. Maharjan M., S. Bhandari, I. Singh and S.C. Mishra. Prevalence of otitis media in school going children in Eastern Nepal. Kathmandu Univ Med J (KUMJ). 2006;4(4): p. 479-82.

16. Rupa V., A. Jacob and A. Joseph. Chronic suppurative otitis media: prevalence and practices among rural South Indian children. Int J Pediatr Otorhinolaryngol. 1999; 48(3): p. 217-21.

17. Elango S., G.N. Purohit, M. Hashim and R. Hilmi. Hearing loss and ear disorders in Malaysian school children. Int J Pediatr Otorhinolaryngol. 1991;22(1): p. 75-80.

18. Hatcher J., A. Smith, I. Mackenzie, S. Thompson, I. Bal, I. Macharia, P. Mugwe, C. Okoth-Olende, H. Oburra, Z. Wanjohi and et al. A prevalence study of ear problems in school children in Kiambu district, Kenya, May 1992. Int J Pediatr Otorhinolaryngol.1995;33(3): p. 197-205.

19. Nepali R. and B. Sigdel. Prevalence of ENT diseases in children: Hospital based study. The Internet Journal Otorhinolarynglogy. 2012;14(2): p. 1-5.

20. Sharma, H., V. Bhusan, D. Dayal and S. Mishra. Preliminary study of hearing handicap in school-going children. Indian J Otolaryngology-Head Neck Surgery. 1992. 30: p. 119-124.

21. Morris P.S., A.J. Leach, P. Silberberg, G. Mellon, C. Wilson, E. Hamilton and J. Beissbarth. Otitis media in young Aboriginal children from remote communities in Northern and Central
Australia: a cross-sectional survey. BMC Pediatr. 2005;5: p. 27.

22. Shrestha, R., K. Baral and N. Weir. Community ear care delivery by community ear assistants and volunteers: a pilot programme. J Laryngol Otol. 2001;115(11): p. 869-73.

23. Suman SY. Prevalence of ENT disorders in children: A tertiary medical care study. Online Journal of Otolaryngology. $2015 \mathrm{Jul}$ $1 ; 5(3): 16$.

24. Guarisco J.L. and H.D. Graham, 3rd. Epistaxis in children: causes, diagnosis, and treatment. Ear Nose Throat J, 1989; 68(7): p. 522, 528-30, 532 passim.

25. Olaleye O., F. Arfeen, M. Watts, O. Lyne, H. Sharp, M. Black and D. Mitchell. A seasonal variation to epistaxis in East Kent, UK. Internet Journal of Otorhinolaryngology. 2011;12(2).

26. Danielides V., N. Kontogiannis, A. Bartzokas, C.J. Lolis and A. Skevas. The influence of meteorological factors on the frequency of epistaxis. Clin Otolaryngol Allied Sci. 2002;27(2): p. 84-8.

27. Gibson, P.G., J.E. Stuart, J. Wlodarczyk, L.G. Olson and M.J. Hensley. Nasal inflammation and chronic ear disease in Australian Aboriginal children. J Paediatr Child Health. 1996; 32(2): p. 143-7. 